\title{
Vector Control and Modeling of Modular Multilevel High Voltage Converter for Rail Vehicle Traction
}

\author{
Yu Zheng ${ }^{1}$, Changxiu Yang ${ }^{1 *}$, Tiefeng Peng ${ }^{2 *}$, Liujian Zhang ${ }^{2}$ \\ ${ }^{1}$ Chongqing Vocational College of Transportation, Chongqing, China; \\ ${ }^{2}$ Shenzhen Possibler Technology Co., Ltd, Shenzhen, China \\ * Email: C. Yang, cvct_cqjy@163.com; T. Peng, pengtiefeng@cqu.edu.cn
}

Received: June 30, 2021. Revised: December 4, 2021. Accepted: January 12, 2022. Published: January 14, 2022.

\begin{abstract}
Rail transit plays an important role in the social and economic life of China and even all countries in the world, especially some populous countries or regions. The traction drive system of rail vehicle provides three-phase AC with adjustable voltage and frequency for the traction motor, controls the speed and torque of the traction motor, and then controls the operation of the vehicle. The modular multilevel converter has the advantages of low harmonic, good power quality of output waveform, high reliability, no input filtering and power compensation, and is suitable in the field of frequency conversion. In this work, the open-loop scalar control and vector closed-loop control of modular multi-level high-voltage inverter were adopted. It was found that driven by modular multi-level variable frequency vector control system, asynchronous motor not only has less harmonic content of voltage and current waveform, but also its speed regulation characteristics have been improved.
\end{abstract}

Keywords-Traction transmission system; Rail vehicle; High Voltage; Converter

\section{INTRODUCTION}

$\mathrm{T}$ HE AC speed regulation technology can improve the automation level, improve the process flow, enhance product quality and labor productivity. Variable frequency speed regulation technology has excellent speed regulation and braking performance, high efficiency, high power factor and good energy-saving effect, and has a good development prospect. The frequency converter can meet the requirements of motor speed regulation in rail transit, improve the speed of rail transit vehicles, save energy and reduce production cost. The motor [1-4] can save about $30 \%$ of the electric energy [5] on average at present, if the frequency converter was applied. Therefore, the input and use of the inverter is a suitable option for energy saving. The traction drive system [6-11] for rail vehicles mainly includes traction converter, traction motor and gear drive system. The traction inverter [12-14] controls the power semiconductor element (IGBT) through the gate drive unit, converts the intermediate $\mathrm{DC}$ into three-phase $\mathrm{AC}$ to supply the asynchronous traction motor, controls the motor rotation, and then drives the whole train forward.

Modular multi-level high-voltage inverter has small harmonic pollution to the power grid, good power quality of output waveform, high reliability, no input filtering and power compensation, no torque ripple, no common mode voltage and other problems caused by harmonics. It is also known as perfect harmonic free inverter, which is suitable for ordinary asynchronous motors. Modular multi-level high-voltage converter [15] uses several low-voltage power units in series to achieve high-voltage output. Compared with two-level and three-level converters, it has higher output level and better sinusoidal output waveform. In order to reduce the harmonic of input current, the phase-shifting input transformer of frequency converter adopts a variety of structures. The high voltage frequency conversion system has 15 power units, which are powered by 15 secondary windings of the phase-shifting input transformer, and each of the three windings is a phase group, and each phase group is $12^{\circ}$ different from each other. Theoretically, the input current waveform is close to sine wave, and the total current harmonic distortion rate is less than $1 \%$.

According to the principle that the electric energy from catenary is converted into mechanical energy through energy conversion, the key of motor control [1-4, 9, 14, 16-19] is the control of electromagnetic torque. The reason why DC motor has good control performance is that its torque is easy to control. The situation of asynchronous motor is complex. The torque of induction motor is related not only to air gap flux and rotor current, but also to the power factor of rotor current. Vector control is a high-performance asynchronous motor control method. Due to the complexity of its torque, it brings difficulties to the control of asynchronous motor [20-25]. The idea is to decouple the stator current into excitation component 
and torque component through coordinate transformation. The two components are independent of each other. By controlling the magnetic field and torque respectively, the purpose of controlling the magnetic field and torque can be achieved, so that the asynchronous motor control has the same excellent performance as the DC motor control. In this work, the open-loop control systems with constant voltage frequency ratio were studied, and their control performance was examined by simulations.

\section{Establishment of Modular Multi-level High Voltage INVERTER MODEL}

\section{A. Circuit Model of Modular Multi-level High Voltage}

\section{Inverter}

Modular multi-level high-voltage converter uses several low-voltage power units in series to realize high-voltage output. Compared with two-level and three-level converters, it has more output levels and better sinusoidal output waveform, as shown in Fig. 1.

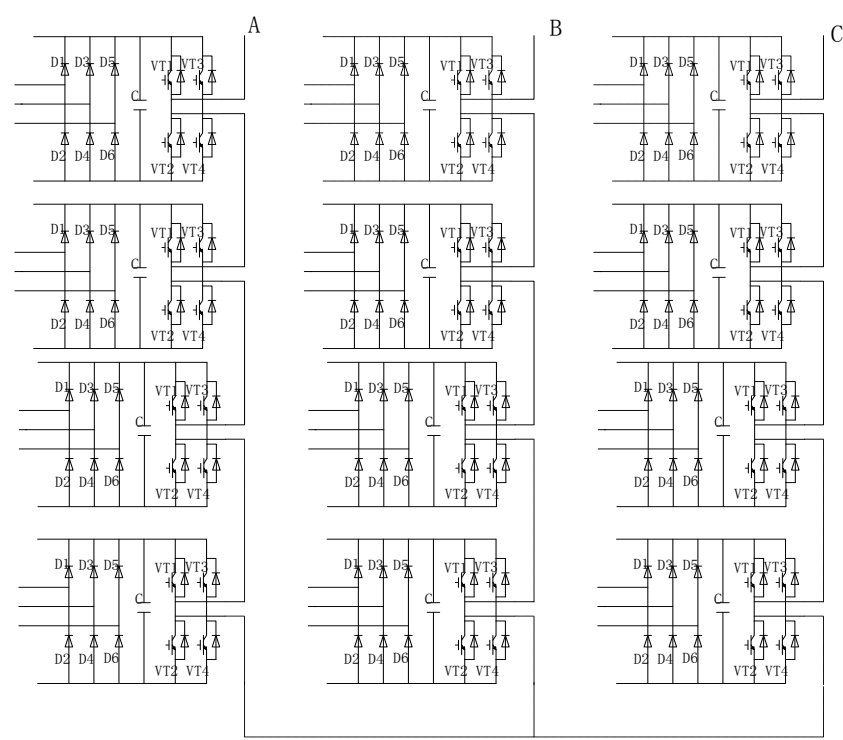

Figure 1. Circuit Structural diagram of the modular multi-level high voltage inverter.

Assuming that the number of power units in series in each phase is $\mathrm{N}$, the number of output phase voltage levels is as follow:

$$
M=2 N+1
$$

$H$-bridge switching function is as follow:

$$
H_{\mathrm{k}}= \begin{cases}1 & S_{1} \\ 0 & S_{2} / S_{3}(k=1,2,3 \ldots N) \\ -1 & S_{4}\end{cases}
$$

Where $H$ is the switch state, the definition is shown in Table 1 , where $(\mathrm{k}=1,2,3, \ldots, N), V_{\mathrm{k} 1}$ to $V_{\mathrm{k} 4}$ represent the switching states of VT1 to VT4, respectively, for the $k$ th power unit in Fig.
1.

Table 1. Switch status of modular multi-level high-voltage inverter.

\begin{tabular}{l|llll}
\hline & $V_{\mathrm{k} 1}$ & $V_{\mathrm{k} 2}$ & $V_{\mathrm{k} 3}$ & $V_{\mathrm{k} 4}$ \\
\hline$S_{1}$ & On & Off & Off & On \\
$S_{2}$ & On & Off & On & Off \\
$S_{3}$ & Off & On & Off & On \\
$S_{4}$ & Off & On & On & Off \\
\hline
\end{tabular}

When the DC bus voltage of H-bridge unit is $\mathrm{V} 0$, the single-phase output voltage could be expressed as:

$$
V_{\mathrm{XN}}=\sum_{k=1}^{N} H_{\mathrm{k}} \times V_{0}(X: A / B / C)
$$

The circuit structure of the power unit is shown in Fig. 2. Its working principle is as follows: after the three-phase AC is rectified by the diode uncontrolled full bridge rectifier circuit, the DC bus voltage is formed by the filter capacitor. The output side is the H-bridge single-phase inverter circuit composed of four IGBT modules, and the output voltage of variable voltage and frequency conversion is obtained by PWM modulation. Because the rectifier part of power unit is diode without control rectifier structure, it cannot achieve energy feedback, so it cannot operate in four quadrants. The filter capacitor provides the required reactive power for the motor, so the input power factor of the power unit can reach above 0.95 without power factor compensation.

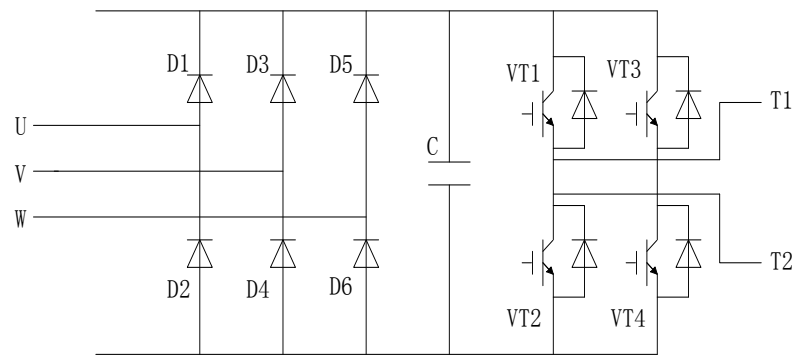

Figure 2. Structure diagram of circuit for the power unit [20].

\section{B. Modulation Algorithm of Modular Multi-level High Voltage Inverter}

When five power units are connected in series, SPWM modulation is completed by five triangular carriers and a pair of inverted sinusoidal modulated wave signals. The shape of the five triangular carriers is the same, but the phase angle is Ts/5 in turn, Ts is the carrier period. The phase of the left arm modulation wave is the same as that of the output voltage, but the phase of the right arm modulation wave is the opposite, as shown in Fig. 3. The left arm is the bridge arm composed of VT1 and VT2 in Fig. 2, and VT3 and VT4 constitute the right 
arm. They complete SPWM modulation by triangular carrier and a pair of inverted sinusoidal modulation wave signals respectively.

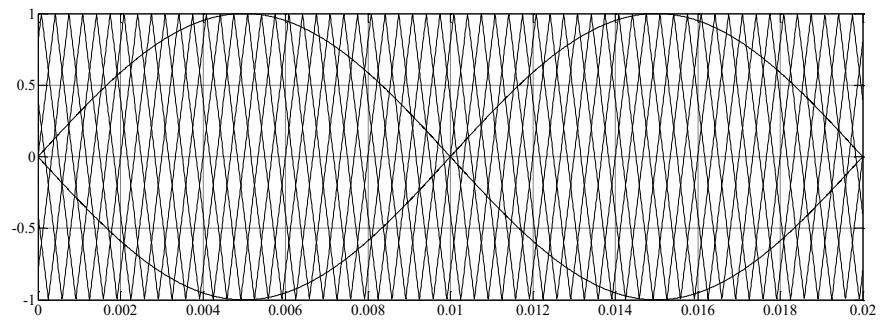

Figure 3. Schematic diagram of the working principle for phase modulation.

By Fourier decomposition of the output voltage of the left leg of A-phase single power unit, the output voltage relationship of the left leg of the power unit can be obtained as

$U_{a 11}=\frac{M E}{2} \cos (\omega t)+\frac{2 E}{\pi} \sum_{m=1}^{\infty} \sum_{n=-\infty}^{\infty} \frac{1}{m}\left\{\sin \left[(m+n) \frac{\pi}{2}\right] J_{\mathrm{n}}\left(m \frac{\pi}{2} M\right) \cos \left(m \omega_{\mathrm{c}} t\right.\right.$

Where: E-DC bus voltage of power unit, $\mathrm{M}-$ Modulation ratio, $\omega$-frequency of output fundamental voltage, $\omega_{\mathrm{c}}$ - frequency of triangular carrier, $\mathrm{m}$ and $\mathrm{n}$-Harmonic number, $\mathrm{J}_{\mathrm{n}}$-Bessel function of order $\mathrm{n}$ of the first kind.

As the phase difference between the left and right arms of the same power unit is $180^{\circ}$, the expression of the output voltage of a single power unit in phase $\mathrm{A}$ is as follow:

$U_{\mathrm{a} 1}=U_{\mathrm{a} 11}-U_{\mathrm{a} 12}=M E \cos (\omega t)+\frac{4 E}{\pi} \sum_{m=1}^{\infty} \sum_{n=-\infty}^{\infty} \frac{1}{m} \cdot\left\{\cos [(m+n+1) \pi] J_{2 \mathrm{n}-1} m \pi M\right.$ $\left.\cdot \cos \left[2 m \omega_{\mathrm{c}} t+(2 n-1) \omega t\right]\right\}$

When $N$ power units are in series, the expression of output phase voltage is:

$U_{\mathrm{a}}=\sum_{i=1}^{N} U_{\mathrm{ai}}=N M E \cos (\omega t)+\frac{4 E}{\pi} \sum_{m=1}^{\infty} \sum_{n=-\infty}^{\infty} \frac{1}{m} \cdot\left\{\cos [(m+n+1) \pi] J_{2 \mathrm{n}-1} m \pi M\right.$

$\left.\cdot \sum_{i=1}^{N} \cos \left[2 m\left(\omega_{\mathrm{c}} t+\frac{i \pi-\pi}{N}\right)+(2 n-1) \omega t\right]\right\}$

For a single power unit, the output voltage harmonics are concentrated near 2 times the carrier frequency, while when five power units are connected in series, the output voltage harmonics are concentrated near 10 times the carrier frequency. Thus, even if the triangular carrier frequency of each power unit is not high, the whole system has a higher equivalent carrier frequency, which can reduce the loss of power switch.

The two modulated waves of the power unit are provided by the two phases, respectively. Different from the in-phase modulation, the modulation wave of the left and right arms of the power unit changes: the phase of the modulation wave of the left arm is the same as that of the output voltage, while the phase angle of the modulation wave of the right arm lags 120 degrees, as shown in Fig. 4. Taking the modulation wave of left and right bridge arms of phase a power unit as an example, the expression is as follows:

$$
\left\{\begin{array}{l}
f_{a 1}=M \sin (\omega t) \\
f_{a 2}=M \sin (\omega t-2 \pi / 3)
\end{array}\right.
$$

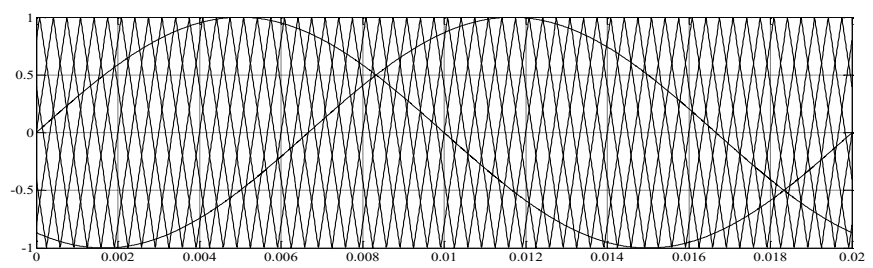

Figure 4. Schematic diagram of out phase modulation principle.

Then the output voltage of single power unit and phase A woyld meet the following requirements:

$$
\left\{\begin{array}{l}
U_{a 1}=\frac{\sqrt{3}}{2} M E \sin (\omega t+\pi / 6) \\
U_{\mathrm{AN}}=\sum_{n=1}^{5} U_{\mathrm{an}} M E \sin (\omega t+\pi / 6)
\end{array}\right.
$$

\section{Realization of Vector Control Method}

In the two phase arbitrary rotating coordinate system (dq coordinate system), the mathematical model of asynchronous motor can be expressed as the following matrix equation:

Torque equation

$$
T_{\mathrm{e}}=n_{\mathrm{p}} L_{\mathrm{m}}\left(i_{\mathrm{sq}} i_{\mathrm{rd}}-i_{\mathrm{sd}} i_{\mathrm{rq}}\right)
$$

Equation of motion

$$
T_{\mathrm{e}}=T_{\mathrm{L}}+\frac{J}{n_{\mathrm{p}}} \frac{d_{\omega_{\mathrm{r}}}}{d t}
$$

Where: $i_{\text {sd }}-\mathrm{d}$ axis component of stator current; $i_{\mathrm{sq}}-\mathrm{q}$ axis component of stator current; $i_{\text {rd }}-\mathrm{d}$ axis component of rotor current; $i_{\mathrm{rq}}$ - $\mathrm{q}$ axis component of rotor current; $L_{\mathrm{m}}$ - Mutual inductance of two phases winding; $n_{\mathrm{p}}$-Pole pair; $J$-Moment of inertia; $\omega_{\mathrm{r}}$-Angular velocity of motor rotor.

The mathematical model of vector control is established in the synchronous rotating coordinate system based on rotor field orientation. The vector control is changed into scalar control in the synchronous rotating coordinate system, and the nonlinear decoupling in the magnetic field orientation is used to improve the dynamic characteristics of the system. In the case of rotor magnetic field orientation, the basic equation of voltage in MT coordinate system is as follows: 


$$
\left.\left\lfloor\begin{array}{c}
U_{\mathrm{sM}} \\
U_{\mathrm{sT}} \\
0 \\
0
\end{array}\right\rfloor=\left\lfloor\begin{array}{cccc}
L_{\mathrm{s}} P+R_{\mathrm{s}} & -\omega_{\mathrm{s}} L_{\mathrm{s}} & L_{\mathrm{m}} P & -\omega_{\mathrm{s}} L_{\mathrm{m}} \\
L_{\mathrm{s}} \omega_{\mathrm{s}} & R_{\mathrm{s}}+L_{\mathrm{s}} P & \omega_{\mathrm{s}} L_{\mathrm{m}} & L_{\mathrm{m}} P \\
L_{\mathrm{m}} P & 0 & R_{\mathrm{r}}+L_{\mathrm{r}} P & 0 \\
\omega_{\mathrm{sl}} L_{\mathrm{m}} & 0 & \omega_{\mathrm{sl}} L_{\mathrm{r}} & R_{\mathrm{r}}
\end{array}\right\rfloor \mid \begin{array}{c}
i_{\mathrm{sM}} \\
i_{\mathrm{sT}} \\
i_{\mathrm{rM}} \\
i_{\mathrm{rT}}
\end{array}\right\rfloor
$$

The flux linkage equation is as follows

$$
\left[\begin{array}{l}
\psi_{\mathrm{sM}} \\
\psi_{\mathrm{sT}} \\
\psi_{\mathrm{rM}} \\
0
\end{array}\right]=\left[\begin{array}{cccc}
L_{\mathrm{s}} & 0 & L_{\mathrm{m}} & 0 \\
0 & L_{\mathrm{s}} & 0 & L_{\mathrm{m}} \\
L_{\mathrm{m}} & 0 & L_{\mathrm{r}} & 0 \\
0 & L_{\mathrm{m}} & 0 & L_{\mathrm{r}}
\end{array}\right]\left[\begin{array}{l}
i_{\mathrm{sM}} \\
i_{\mathrm{sT}} \\
i_{\mathrm{rM}} \\
i_{\mathrm{rT}}
\end{array}\right]
$$

\section{RESULTS AND DISCUSSION}

The main circuit did not consider the phase-shifting transformer, and the power unit was powered by DC power supply. Each phase was composed of 5 power units in series. The modeling and simulations were illustrated as in Fig. 5.

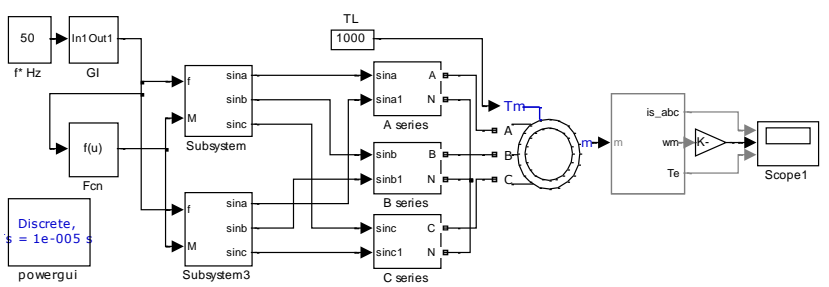

Figure 5. Simulations of open loop control system with constant voltage frequency ratio.

The third-harmonic injection was added to the pulse generation module, the illustration for modulation signal generation module is shown in Fig. 6. The parameters [20] used in modeling and simulations were as follow. DC power supply $U_{\mathrm{d}}=930 \mathrm{~V}$, line voltage $U=6 \mathrm{kV}$, frequency $f=50 \mathrm{~Hz}$, stator resistance $R_{\mathrm{s}}=2 \Omega$, stator leakage inductance $L_{\mathrm{sl}}=22.3 \mathrm{mH}$, rotor resistance $R_{\mathrm{r}}=1.9 \Omega$, rotor leakage inductance $L_{\mathrm{rl}}=15.9 \mathrm{mH}$, excitation inductance $L_{\mathrm{m}}=748 \mathrm{mH}$, moment of inertia $J=48 \mathrm{~kg}$ $\mathrm{m} 2$, pole pair $n_{\mathrm{p}}=2$, given speed $1450 \mathrm{r} / \mathrm{min}$, given load $T_{\mathrm{L}}=1000 \mathrm{~N} \mathrm{~m}$.

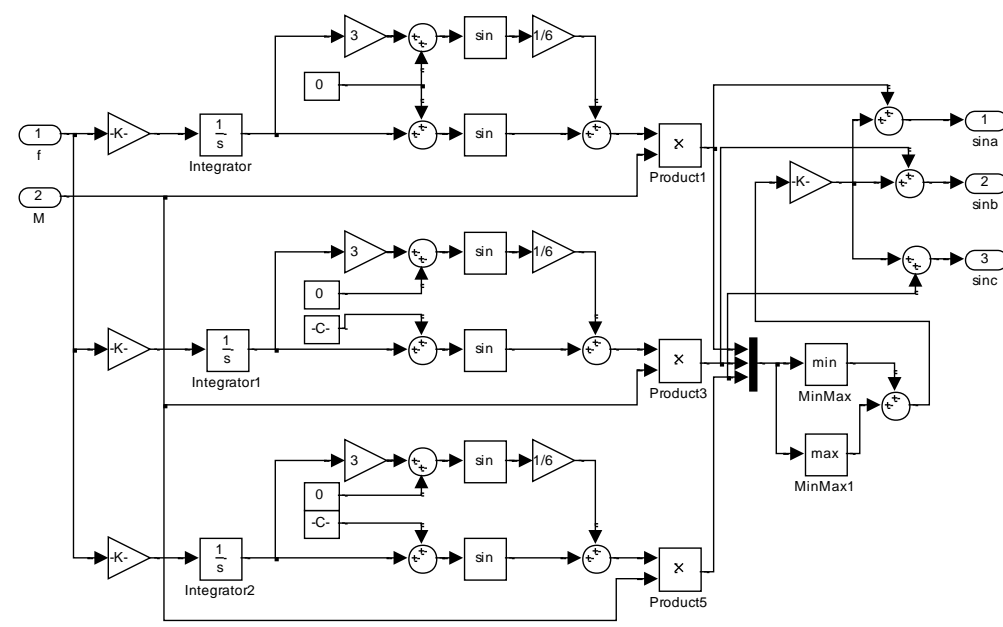

Figure 6. Schematic diagram of modulation signal generation module injected with 3rd harmonic [20].

As mentioned, the main circuit of the simulation model does not consider the phase-shifting transformer, the power unit is powered by DC power supply, each phase is composed of five power units in series, and the third harmonic is injected into the input.
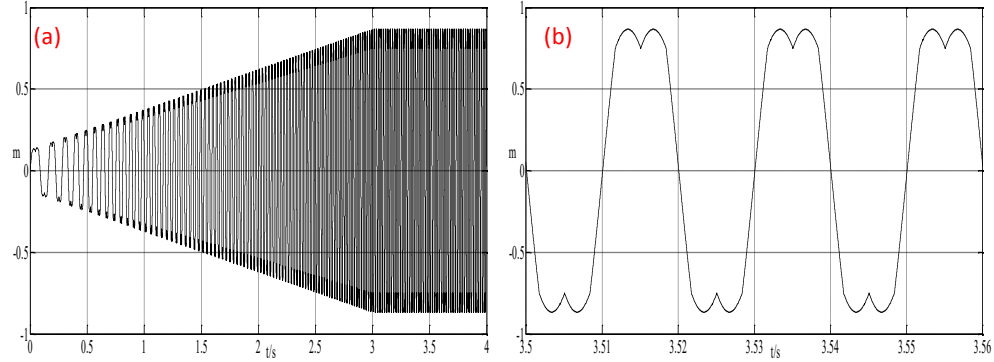

Figure 7. Modulation wave (a), and its amplified waveform (b) for motor control model.

The modulation waveform is shown in Fig. 7, it showed the non-sinusoidal state, as to waveform injected 3 harmonics. When the system started, the amplitude increased continuously, and the amplitude remains unchanged after 3 seconds.
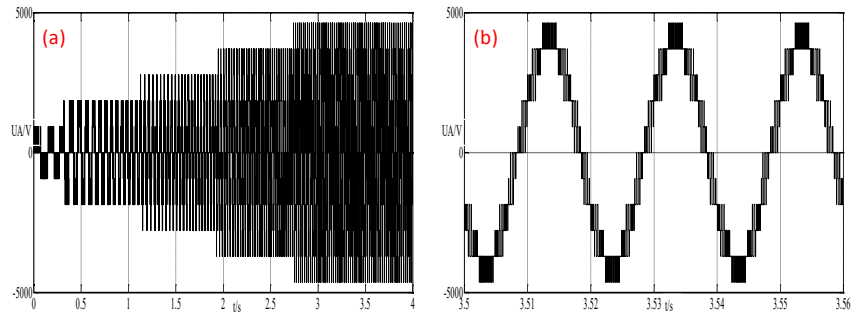

Figure 8. Phase voltage waveform (a) and its amplified waveform (b) of inverter output for motor control model.

As can be seen from Fig. 8, with the increase of time, the phase voltage amplitude of inverter output increases gradually, and remained unchanged after 2.8 seconds. At the same time, it can be found that the level number of output phase voltage is eleven, which satisfies the relationship of $2 N+1$ when the 
number of cascades is $N$.
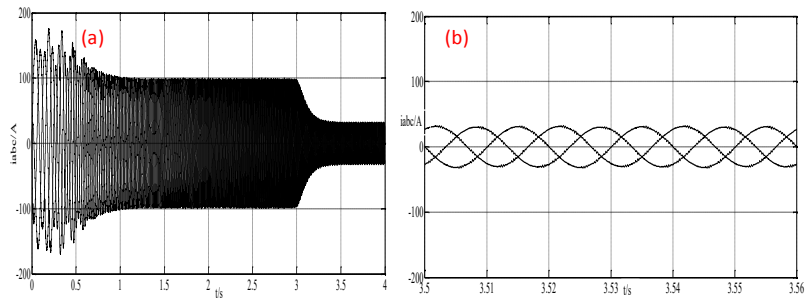

Figure 9. Three phase stator current waveform (a) and its amplified waveform (b) for motor control model.

The three-phase stator current gradually decreases with the increase of time, which is stable after 3.5 seconds, as shown in Fig. 9. It could be found that when the system starts up, the peak current was about $100 \mathrm{~A}$, and the effective value is $71 \mathrm{~A}$, which is about 1.3 times of the rated current. The starting current is small, which can reduce the impact on the power grid. According to the enlarged three-phase current waveform, the stable current waveform is a perfect sine wave with a phase difference of 120 degrees.
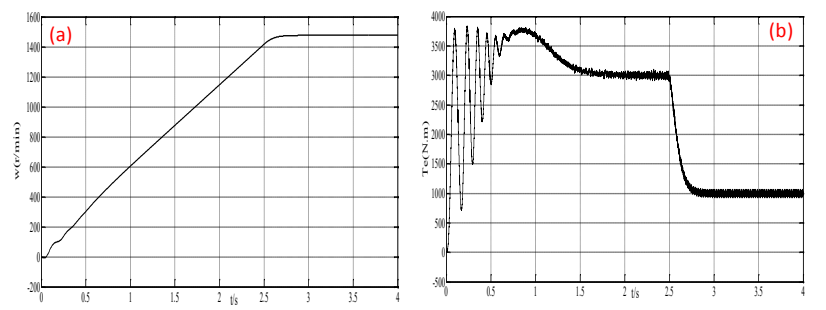

Figure 10. Speed waveform (a) and torque waveform (b) for motor control model.

It can be seen (Fig. 10) from the speed waveform that the motor speed increases gradually after the system starts, and the motor starts after 2.5 seconds, and then the motor speed basically reaches a stable speed, which is about $1450 \mathrm{r} / \mathrm{min}$. It can be seen from the output torque waveform of the motor that in the process of motor speed-up, except for 0.5 seconds of starting, the motor torque fluctuates greatly, and the other time torque basically remains constant, about $3100 \mathrm{~N} \cdot \mathrm{m}$, about 1.05 times of the rated torque. After the motor starts, the torque gradually tends to be stable, about $1000 \mathrm{~N} \cdot \mathrm{m}$. Therefore, in the process of variable frequency starting, the motor starting torque is small, the fluctuation is small, the starting torque is stable, and the impact on the motor and its load is small.

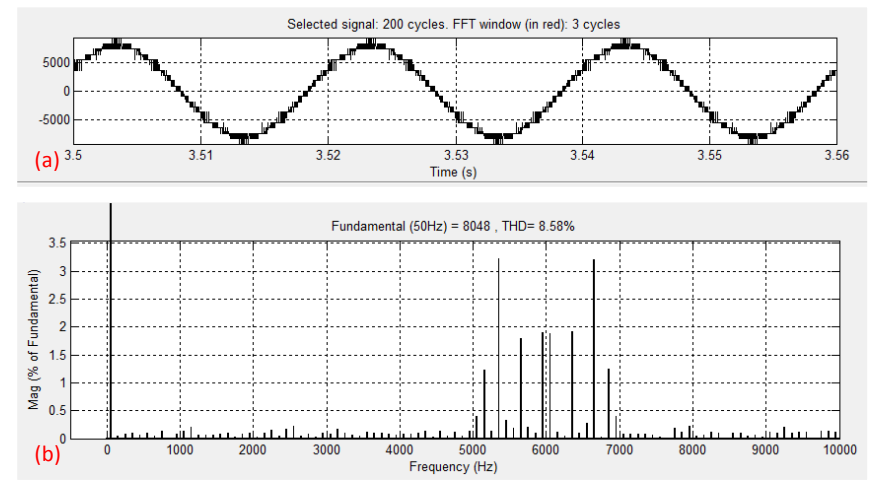

Figure 11. Time domain diagram (a) and frequency domain diagram (b) of line voltage.

When the inverter operates at $50 \mathrm{~Hz}$, the harmonic distribution of the output line voltage is shown in Fig. 11. It can be seen from the figure that the amplitude of line voltage is about $10000 \mathrm{~V}$, and its low order harmonic content is very small, harmonic is mainly concentrated around $6000 \mathrm{~Hz}$ corresponding to the output equivalent switching frequency, ranging from $5000 \mathrm{~Hz}$ to $7000 \mathrm{~Hz}$, the highest harmonic content is $3.3 \%$. The THD of the output line voltage is $8.6 \%$, which meets the power supply requirements of ordinary motors.

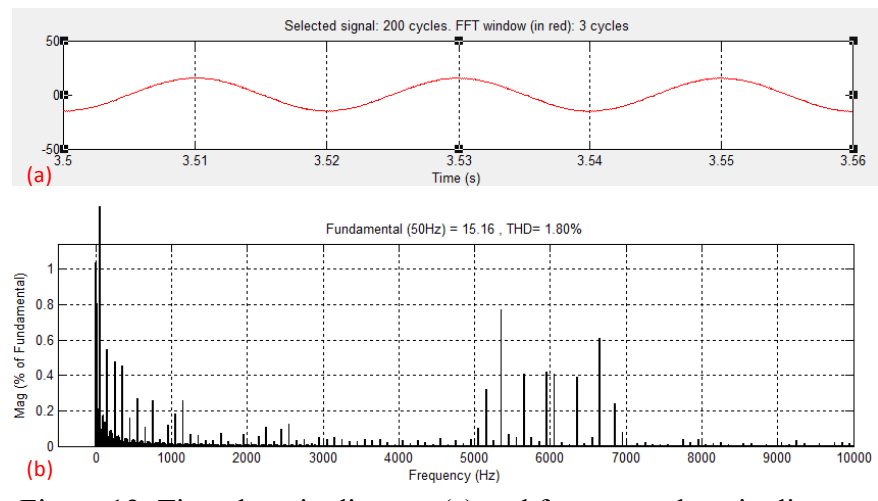

Figure 12. Time domain diagram (a) and frequency domain diagram (b) of output current.

Fig. 12 showed the spectrum distribution of the output current when the system operated at $50 \mathrm{~Hz}$. It can be seen from Fig. 12 that the current of the motor in steady state has good sinusoidal degree, and the waveform is relatively smooth. Its amplitude is about $20 \mathrm{~A}$, and the total current THD is only $1.8 \%$. The current harmonics are mainly concentrated around $6000 \mathrm{~Hz}$ corresponding to the output equivalent switching frequency and below $1000 \mathrm{~Hz}$, and the other harmonic current content is very small. 


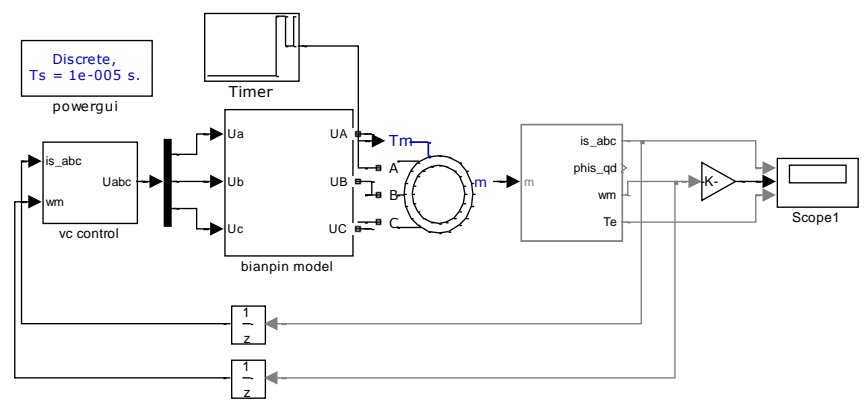

Figure 13. Simulation model diagram of vector closed loop control system.

Fig. 13 shows the simulation model of vector control closed-loop system. It consisted of vector control module, series power unit module, SPWM pulse generation module and motor module.

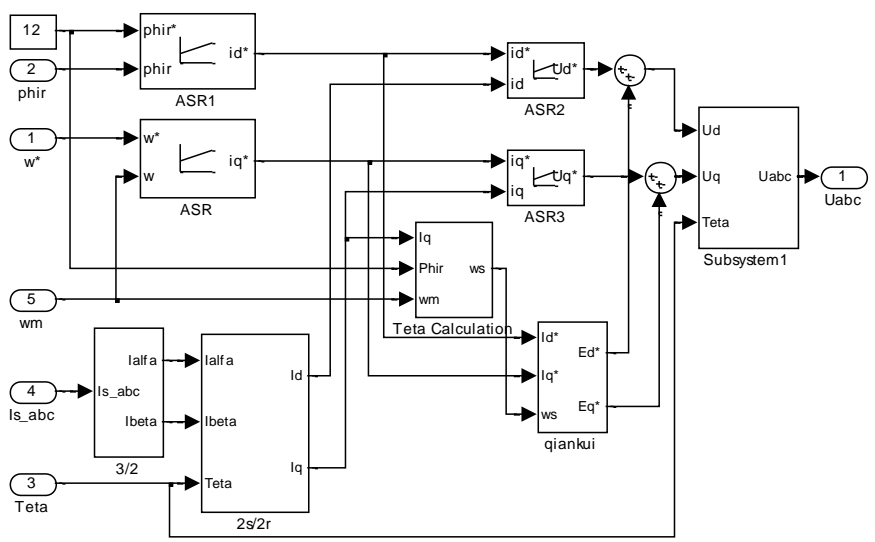

Figure 14.Core algorithm module of vector control.

As shown in Fig. 14, it is the core algorithm module of vector control, which is an asynchronous motor vector control system with double closed loops of flux and speed.
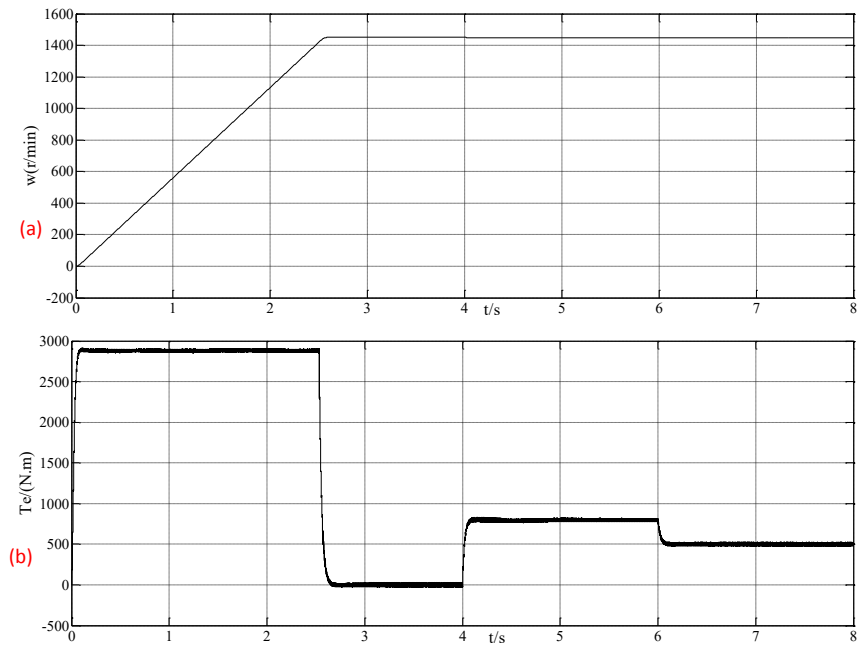

Figure 15. Speed waveform (a) and torque waveform (b) for motor vector control model.

As shown in Fig. 15, with the change of time, the motor speed gradually increases, and the speed is basically stable at 1450 $\mathrm{r} / \mathrm{min}$ in about $3 \mathrm{~s}$. In the process of increasing and decreasing load, the fluctuation of speed is small, the speed almost unchanged, and always maintained at the given command value, and the torque also has fast response.
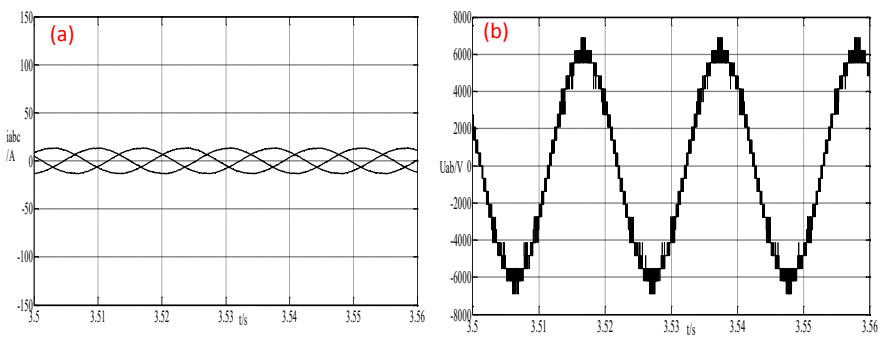

Figure 16. Enlarged diagram of stator three-phase current waveform (a) and frequency converter line voltage waveform (b) for motor vector control model.

It can be seen from Fig. 16a that the waveform of stator three-phase current after stabilization could be a perfect sine wave. As shown in Fig. 16b, the line voltage output waveform of high-voltage inverter is 21 levels, which meets the relationship between the number of levels and the number of cascaded units, i.e., $4 N+1$, and its waveform is closer to sine wave.

(a)

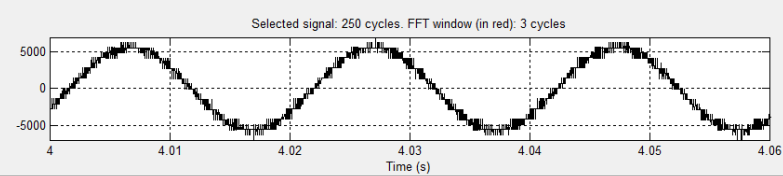

(b)

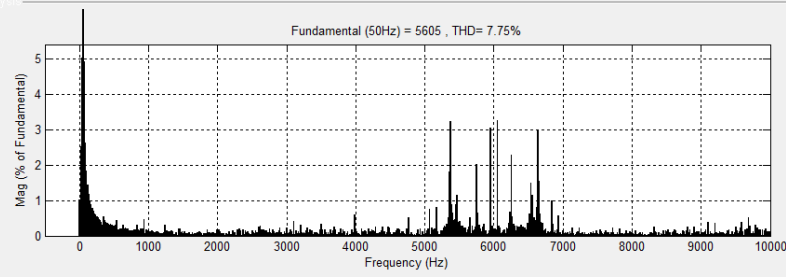

Figure 17. Time domain diagram (a) and frequency domain diagram (b) of Line voltage for vector control.

It can be seen from the Fig. 17 that the voltage distortion rate is $7.75 \%$.

(a)

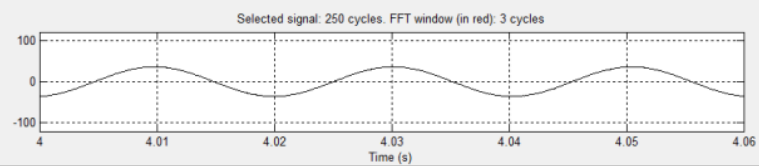

(b)

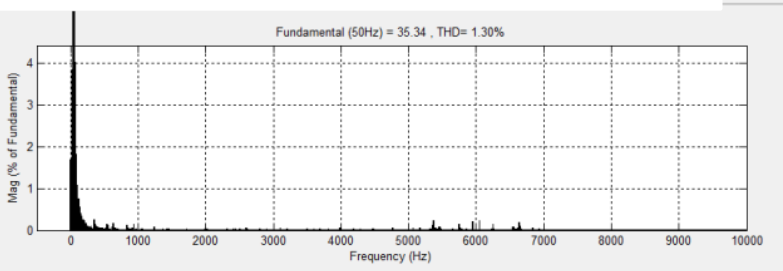

Figure 18. Time domain diagram (a) and frequency domain diagram (b) of Line current for vector control.

Fig. 18 shows that the total current distortion rate is $1.3 \%$. 
Compared with the open-loop control system, the voltage and current harmonics of the vector closed-loop control system are smaller.

It can be seen from the simulation results that during no-load start-up, the output voltage of the frequency converter gradually increases and the speed shows an upward trend. During the starting process, the three-phase current passes through the stator winding to establish a rotating magnetic field in the asynchronous motor. The amplitude of the three-phase current in the stator of the motor is large and has not reached the stable value. When the flux linkage reaches the steady-state value, the motor outputs a large torque to increase the motor speed. In about 3S, the speed reaches the given value, stabilizes at 1450r / $\mathrm{min}$, and the torque is zero. When the motor increases or decreases the load, the electromagnetic torque can respond quickly, and finally keep consistent with the load torque. The speed drop is very small, almost unchanged, and is always maintained at the given command value, which proves that the system has strong anti-load disturbance ability. After stabilization, the three-phase stator current waveform is almost perfect sine wave. It can be seen that under the vector control system, the motor speed regulation performance is excellent, which is greatly improved compared with the open-loop control.

\section{CONCLUSIONS}

Compared with other transportation modes such as highway, aviation and sea transportation, rail vehicle transportation has the advantages of long distance, low cost, high safety rate, large traffic volume and low environmental pollution. The traction transmission system realizes the speed regulation of the rail vehicle, which is very important for the rail vehicle system. The traction drive system adjusts the running speed and traction force of the train by controlling the frequency and amplitude of the input voltage of the traction motor. In this work, the open-loop scalar control and vector closed-loop control of modular multi-level high-voltage inverter were studied. The constant voltage frequency ratio open-loop control of modular multi-level high-voltage converter has the advantages of less harmonic pollution on the input side, high efficiency, output voltage close to sine wave, simple structure and easy implementation. Compared with the constant voltage frequency ratio open-loop control, the vector closed-loop control system has less harmonic content of voltage and current, and the speed regulation performance of motor is also improved.

\section{ACKNOWLEDGMENT}

This work was supported by financial support of Science and Technology Project of Chongqing Education Commission (KJ1505702), and Construction Project of Chongqing High Level Vocational Schools and Specialty Groups (Chongqing Vocational College of Transportation).

\section{References}

[1] Luo, J., S. Zhu, and W. Zhai, Theoretical modelling of a vehicle-slab track coupled dynamics system considering longitudinal vibrations and interface interactions. Vehicle System Dynamics, 2020.

[2] Qi, Y. and H. Dai, Influence of motor harmonic torque on wheel wear in high-speed trains. Proceedings of the Institution of Mechanical Engineers Part F-Journal of Rail and Rapid Transit, 2020. 234(1): p. 32-42.

[3] Wang, Z., et al., Coupled dynamic behaviour of a transmission system with gear eccentricities for a high-speed train. Vehicle System Dynamics, 2020.

[4] Yao, B., et al., Multitimescale Reliability Evaluation of DC-Link Capacitor Banks in Metro Traction Drive System. Ieee Transactions on Transportation Electrification, 2020. 6(1): p. 213-227.

[5] J.Liu, Y.J., Modeling and Analysis of Vehicle Energy Consumption. Engineering Intelligent Systems, 2021. 29(2): p. 97-102.

[6] Mao, Z., et al., Adaptive Fault-Tolerant Sliding-Mode Control for High-Speed Trains With Actuator Faults and Uncertainties. Ieee Transactions on Intelligent Transportation Systems, 2020. 21(6): p. 2449-2460.

[7] Scheepmaker, G.M. and R.M.P. Goverde, Energy-efficient train control using nonlinear bounded regenerative braking. Transportation Research Part C-Emerging Technologies, 2020. 121.

[8] Su, S., et al., An Energy-Efficient Train Operation Approach by Integrating the Metro Timetabling and Eco-Driving. Ieee Transactions on Intelligent Transportation Systems, 2020. 21(10): p. 4252-4268.

[9] Wang, J., et al., Nonsmooth Dynamics of a Gear-Wheelset System of Railway Vehicles Under Traction/Braking Conditions. Journal of Computational and Nonlinear Dynamics, 2020. 15(8).

[10] Wang, P., et al., Train trajectory optimization for improved on-time arrival under parametric uncertainty. Transportation Research Part C-Emerging Technologies, 2020. 119.

[11] Yildirim, D., et al., Full-Scale Physical Simulator of All SiC Traction Motor Drive With Onboard Supercapacitor ESS for Light-Rail Public Transportation. Ieee Transactions on Industrial Electronics, 2020. 67(8): p. 6290-6301.

[12] Hao, F., et al., Optimal Voltage Regulation and Power Sharing in Traction Power Systems With Reversible Converters. Ieee Transactions on Power Systems, 2020. 35(4): p. 2726-2735.

[13] Kersten, A., et al., Battery Loss and Stress Mitigation in a Cascaded H-Bridge Multilevel Inverter for Vehicle Traction Applications by Filter Capacitors. Ieee Transactions on Transportation Electrification, 2019. 5(3): p. 659-671.

[14] Zhong, Z., et al., Hierarchical Optimization of an On-Board Supercapacitor Energy Storage System Considering Train Electric Braking Characteristics and System Loss. Ieee Transactions on Vehicular Technology, 2020. 69(3): p. 2576-2587.

[15]Zhang, L., The Simulation Research on Sensorless Vector Control System of The Modular Multi-level High-Voltage Inverter. 2014. 
[16] Liu, H., et al., Research on energy-saving characteristics of battery-powered electric-hydrostatic hydraulic hybrid rail vehicles. Energy, 2020. 205.

[17] Liu, J., et al., Wheel/Rail Adhesion State Identification of Heavy-Haul Locomotive Based on Particle Swarm Optimization and Kernel Extreme Learning Machine. Journal of Advanced Transportation, 2020. 2020.

[18] Liu, Y., et al., Dynamic investigation of traction motor bearing in a locomotive under excitation from track random geometry irregularity. International Journal of Rail Transportation, 2021.

[19] Wang, Z., et al., Wheel wear analysis of motor and unpowered car of a high-speed train. Wear, 2020. 444.

[20]Zhang, L., The Simulation Research on Sensorless Vector Control System of The Modular Multi-level High-Voltage Inverter. Southwest Jiaotong University. 2014.

[21] Lei, A., et al., Design optimization of vehicle asynchronous motors based on fractional harmonic response analysis. Mechanical Sciences, 2021. 12(1): p. 689-700.

[22] Wang, X., et al., Control and Modeling of Modular Multi-level High Voltage Converter Vector for Rail Trail Traction. International Core Journal of Engineering, 2021. 7 (5).

[23] Rajput, S., E. Farber, and M. Averbukh, Optimal Selection of Asynchronous Motor-Gearhead Couple Fed by VFD for Electrified Vehicle Propulsion. Energies, 2021. 14(14).

[24] Varatharajan, A., et al., Sensorless Synchronous Motor Drives: A Review of Flux Observer-Based Position Estimation Schemes Using the Projection Vector Framework. Ieee Transactions on Power Electronics, 2021. 36(7): p. 8171-8180.

[25] Zhang, H., Y. Guo, and L. Bai, Study on No-Load Loss and Rotor Contact Resistance of Asynchronous Motor. Ieej Transactions on Electrical and Electronic Engineering, 2021.

$\mathrm{Yu}$ Zheng, Master degree, Associate Professor, he received his master degree from Chongqing University in 2010. His research interests include Rail Transit and Control.

Changxiu Yang, born in Sichuan Province 1987 July, Master degree, Associate Professor, Senior Technician, Dean of the Department of Rail Transit, Chongqing Vocational College of Transportation. From September 2006 to July 2010, he studied Automation, in the area of Traffic Information Engineering and Control, in Southwest Jiaotong University. In September 2010, he was recommended to be graduate student without exam, with the first place in Traffic Engineering, in the field of Information and Control. His research interests include Rail Transit and Control.

Tiefeng Peng, Professor, he received his $\mathrm{PhD}$ from the University of Queensland in 2014. His research area is modeling in science and engineering.

Liujian Zhang, male, master degree, his research interest is electrical engineering and intelligent control.
Creative Commons Attribution License 4.0 (Attribution 4.0 International, CC BY 4.0)

This article is published under the terms of the Creative Commons Attribution License 4.0

https://creativecommons.org/licenses/by/4.0/deed.en US 